\title{
Influence of process variables on quality attributes of jaggery prepared by vacuum pan evaporation technology
}

\author{
Eresh Kumar Kuruba, P.V.K. Jagannadha Rao, D. Khokhar and S. Patel
}

Received : 19.05.2020; Revised : 11.08.2020; Accepted : 11.09 .2020

See end of the Paper for authors' affiliation

Correspondence to :

Eresh Kumar Kuruba Department of Agricultural Processing and Food Engineering, SVCAET\& RS, Indira Gandhi Krishi

Vishwavidyalaya, Raipur

(C.G.) India

Email: eresh5@gmail.com
- ABSTRACT : Jaggery is a solid unrefined, non- centrifugal cane sugar (NCS) with unique colour, flavor and aroma obtained from crushing of cane and evaporating of sugarcane juice. In this paper vacuum pan evaporation method were used sugarcane juice boiling at vacuum pressure $(\mathrm{Vp}: 500-700 \mathrm{~mm}$ of $\mathrm{Hg})$, time $(\mathrm{t}: 60-90 \mathrm{~min})$ and temperature $\left(\mathrm{T}: 100-120^{\circ} \mathrm{C}\right)$. The quality attributes of jaggery developed from vacuum pan evaporator were investigated at different process variables. The developed jaggery were analyzed for physiochemical. Results showed that TSS $\left({ }^{0}\right.$ Brix $)$ and Hardness $\left(\mathrm{H}_{\mathrm{d}}\right)$ increased with increase in vacuum pressure and time, whereas moisture content percentage $(\%)$ and water activity $\left(\mathrm{a}_{\mathrm{w}}\right)$ decreased with increase in vacuum pressure and time at variable temperature of $110^{\circ} \mathrm{C}$. Fuzzy logic method was used to evaluate the sensory characteristic of prepared jaggery.

- KEY WORDS : Jaggery, Vacuum pan, Variables, Temperature, Quality

- HOW TO CITE THIS PAPER : Kuruba, Eresh Kumar, Rao, P.V.K. Jagannadha, Khokhar, D. and Patel, S. (2020). Influence of process variables on quality attributes of jaggery prepared by vacuum pan evaporation technology. Internat. J. Agric. Engg., 13(2) : 188-194, DOI: 10.15740/HAS/ IJAE/13.2/188-194. Copyright@2020: Hind Agri-Horticultural Society. 